\title{
Mısır (Zea mays L.) Fidelerinde Kadmiyum Toksisitesi ile Nitrik Oksit Arasındaki Biyokimyasal İlişkiler
}

\author{
Songül ÇANAKCI-GÜLENGÜL*, Didem DEVECİ, Fadime KARABULUT \\ Firat Üniversitesi, Biyoloji Bölümü, Elazı̆̆ \\ (ORCID: 0000-0002-5731-6175) (ORCID: 0000-0001-8176-8203) (ORCID: 0000-0001-5186-2303)
}

\begin{abstract}
$\ddot{O} z$
Bu çalışmada, 15 günlük mısır (Zea mays L.) fidelerine, önceden farklı sodyum nitroprussid (SNP) $(25$ ve $50 \mu \mathrm{M})$ konsantrasyonları uygulandıktan sonra, bu fidelerin farklı kadmiyum $(25,50$ ve $75 \mu \mathrm{M})$ konsantrasyonlarına karşı verdiği biyokimyasal cevaplar araştırıldı. Fidelere yapılan tüm uygulamalar hidroponik ortamda uygulandı. Kadmiyum (Cd) uygulanan mısır fidelerinin köklerinde ve yapraklarında SNP ön uygulamasız fidelerde, kontrole kıyasla okside glutatyon (GSSG) ve redükte glutatyon (GSH) miktarlarında artma ve SNP ön uygulamalı fidelerde ise azalma tespit edildi. Fidelere uygulanan kadmiyum konsantrasyonları arttıkça, hem SNP ön uygulamasız, hem de SNP ön uygulamalı fidelerde kontrol grubu fidelerine klyasla 16:0 (palmitik asit) yapraklarda ve köklerde artmıştır. Tek başına SNP uygulamalarında, 16:0 üzerinde kontrole kıyasla, $50 \mu \mathrm{M}$ SNP daha az bulunmuştur. Cd uygulamaları ile SNP ön uygulamasız ve SNP ön uygulamalı fidelerde 16:1 (palmioleik asit) yapraklarda genel olarak artarken, bazı konsantrasyonlarda SNP ön uygulamasıyla bu artış hafifletilmiştir. Cd uygulamaları ile SNP ön uygulamasız ve SNP ön uygulamalı fidelerde 18:0 (stearik asit) köklerde ve 18:2 (linoleik asit) kök ve yapraklarda artmıştır. Cd uygulamaları ile SNP ön uygulamasız fidelerde 18:3 (linolenik asit) yaprakta azalırken; SNP ön uygulamalı bazı fidelerde ise 18:3 miktarı yapraklarda artmıştır. Genel olarak 50 $\mu \mathrm{M}$ SNP ön uygulamasının Cd toksisitesini baskılama da $25 \mu \mathrm{M}$ SNP' den daha başarılı bulundu.
\end{abstract}

Anahtar kelimeler: Misır (Zea mays L.), SNP, Nitrik oksit, Kadmiyum toksisitesi.

\section{Investigation of The Relationship Between Cadmium's Toxicity and Nitric Oxide in Corn (Zea mays L.) Plants}

\begin{abstract}
In this study, after 15 day old corn (Zea mays L.) seedlings apply firstly to different concentrations $(25$ and $50 \mu \mathrm{M})$ of sodium nitoprusside (SNP), biochemical responses of these seedlings to different concentrations (25, 50 and 75 $\mu \mathrm{M}$ ) of cadmium are examined. All applications made to seedlings were in hydroponic surroundings. In the amount of reduced glutathione (GSH) and oxide glutathione (GSSG) were increased in the roots and shoots of cadmium (Cd)-administered corn seedlings in SNP non-pretreatment seedlings once compared to the control and they was decreased in SNP pretreatment seedlings. As the cadmium concentrations applied to the seedlings increased both the SNP non-pretreatment and the SNP pretreatment seedlings, 16:0 (palmitic acid) increased in the roots and shoots once compared to the control group seedlings. Only In SNP applications was found less than $50 \mu \mathrm{M}$ SNP at 16:0 once compared to control. With Cd applications, SNP non-pretreatment and SNP pretreatment seedlings generally increased at 16:1 (palmioleic acid) shoots, while at some concentrations this increase was alleviated by pretreatment of SNP. With Cd applications, the 18:0 (stearic acid) increased in roots and the 18:2 (linoleic acid) increased in shoots and roots; at the SNP non-pretreatment and the SNP pretreatment seedlings. With Cd applications, 18:3 (linolenic acid) decreased in shoots in the SNP non-pretreatment shoots; in some the SNP pretreatment seedlings, 18:3 increased by an amount of shoots. In general, $50 \mu \mathrm{M}$ SNP pretreatment was found more successful than $25 \mu \mathrm{M}$ SNP in suppressing Cd toxicity.
\end{abstract}

Keywords: Corn (Zea mays L.), SNP, Nitric oxide, Cadmium toxicity.

\footnotetext{
*Sorumlu yazar: scanakci77@gmail.com

Geliş Tarihi: 12.09.2018, Kabul Tarihi: 04.01.2019
} 


\section{Giriş}

Ağır metaller, ekolojik dengeyi bozan, canlı büyüme ve gelişimini önemli ölçüde zarara uğratan ve çevreyi kirleten temel sebeplerden biridir [1]. Birçok kirlenmede olduğu gibi ağır metal kirlenmesinde de öncelikle etkilenen grup bitkilerdir [2]. Kadmiyum toprakta hareketli bir elementtir ve bitkiler tarafından kolaylıkla alınabilir [3]. NO (nitrik oksit) düşük molekül ağırlığına sahip olup, lipofilik özellikte olduğundan dolayı hücre membranlarından kolayca difüzyona uğrayabilmektedir. Ayrıca çiftlenmemiş elektron taşıması nedeniyle serbest radikal olarak kabul edilir. NO diğer moleküllerle kuvvetli reaksiyonlara girebilen, birkaç saniye yarı ömrü olan fizyolojik haberci molekül olarak da tanımlanmaktadır [4], [5]. Genellikle bitkiye eksojen olarak uygulanan sodyum nitropurissid (SNP) ve sodyum-nitroso-N-asetil-penisilamin (SNAP), hücre için enzimatik olmayan NO vericileridir [6]. Nitrik oksit (NO), bir azot atomu ve oksijen atomunun birleşmesiyle oluşan, hem suda hem de yağda erime özelliğine sahip, renksiz, gaz yapıda bir moleküldür. Dış yörüngesinde paylaşılmamış bir elektron içermesi nedeniyle NO hem radikal özelliği kazanmakta hem de membranlardan kolaylıkla difüzyon edebilmektedir [7]. Nitrik oksit, oldukça önemli biyolojik fonksiyonları yerine getirmek üzere üretilen nitrojen merkezli bir radikaldir. Paylaşılmamış elektron aslında nitrojen atomuna ait ise de, bu elektronun hem nitrojen hem de oksijen atomu üzerinde delokalize olması nedeniyle tam radikal özelliği taşımamaktadır. Bunun sonucu olarak, bilinen diğer radikallere göre reaktivitesi baskılandığından, oldukça uzun ömürlü bir radikaldir [8]. Ağır metallerden biri olan Kadmiyum (Cd), çevre kirliliğindeki önemli bir unsur olarak gündeme gelmiş bir metaldir [9]. Kadmiyum (Cd) gümüş beyazı renginde bir metaldir ve havada hızla kadmiyum oksite dönüşür. Kadmiyum sülfat, kadmiyum nitrat, kadmiyum klorür gibi inorganik tuzları suda çözünür [10]. Kadmiyum normalde topraklarda düşük konsantrasyonlarda bulunan toksik bir elementtir. Kadmiyumun tarım topraklarında bulunması ana metal kaynaklı olabileceği gibi endüstriyel faaliyetler, fosforlu gübreler, lağım atıkları ve atmosferik depozitler gibi insan faaliyetleri sonucunda da olabilir [11]. İnsan faaliyetleri sonucu toprağa ulaşan Cd' nin \% 54-58' i fosforlu gübrelerden, \% 2-5' i atık çamur ve çiftlik gübresi uygulamalarından, \% 39-41' $\mathrm{i}$ ise atmosferik depolanmadan kaynaklanmaktadır [12]. Kadmiyum, bitkilerde strese sebep olan en yıkıcı ağır metallerden birisidir [13]. Aslında kadmiyum biyolojik fonksiyonlar açısından bitkiler için gerekli bir element değildir [14]. İnsan, hayvan ve bitkiler için toksiktir. Diğer ağır metallere göre çok daha fazla (2-20 kat) toksik etkiye sahiptir. Kadmiyum toprakta hareketli bir elementtir ve bitkiler tarafindan kolaylıkla alınabilir [3]. Cd (kadmiyum), $\mathrm{Cr}$ (krom), $\mathrm{Cu}$ (bakır), $\mathrm{Ni}$ (nikel) ve $\mathrm{Zn}$ (çinko) gibi topraktaki bazı ağır metallerin yüksek konsantrasyonları doğal su ve karasal ekosistemlerinin bozulmasına neden olmaktadır. Bitkiler için bazı ağır metaller düşük konsantrasyonlarda önemli mikro besin elementlerdir. Ancak bunların yüksek konsantrasyonları çoğunlukla bitki türlerinin büyümesini engeller, bu da metabolik düzensizliğe sebep olmaktadır. Bazı araştırmacılar, metal zengini topraklarda yetişen bazı bitki türlerinin endemik olduğunu ve toksik dozlardan daha fazlasını tolere edebildiğini bildirmişlerdir [9]. Bu akümülatör bitkiler ağır metalleri inaktif formda biriktirmekte ve bazı özel enzimlerle beraber kendi yaşamsal faaliyetlerini düzenlemektedirler [15]. Ağır metallerin genel olarak bitkilerdeki toksisitesi yaprakta klorozis ve nekrozis oluşumu, kök ve gövde kısımlarının deformasyonu gibi etkiler görülebilmektedir [16].

Bitkiler, ağır metallerin zararlarını tolere edebilecek; ağır metalotiyanin, aminoasit, ferritin, ve fitokelatin gibi moleküllerle kompleks yapılar yaparak hücre duvarları ve vakuol gibi metabolik yollardan uzak bölgelerde biriktirme, antioksidan enzim aktivitelerinin ve antioksidan moleküllerinin miktarlarının artıılması ve hücre membranlarının onarılması gibi birçok savunma mekanizmalarının olduğu belirtilmiştir [17, 18, 19, 20, 21]. Bir diğer çalışmada, çözünebilir seviyelerde prolin, toplam fenol, GSH ve GSH / GSSG oranı, soğuk stresi altında SNP varlığında belirgin bir şekilde artmıştır [22]. Fasülye (Vigna radiata L. cv. BARI Mung-2) fidelerine 5. gün nitrik oksit (SNP $1 \mathrm{mM}$ ) ve $\mathrm{Cd}(\mathrm{CdCl} 2$ $1.5 \mathrm{mM}$ ), 6, gün Cd uygulandı. Fasülye fidelerinin köklerinde ve yapraklarında, Cd stresi altında GSH/GSSG oranı azaldı, MDA (malondialdehit), GSH, GSSG ve prolin içeriğinin arttığı tespit edildi [23]. Soya fasulyesinin hücre süspansiyon kültüründe NO' nun Cd uygulanmasına karşı koruyucu etki göstermiş̧ir. SNP' nin, Lupinus luteus L. (acı bakla) köklerinde hücre bölünmesi üzerine ağır metallerin $\left(\mathrm{PbCl}_{2}\right.$ ve $\left.\mathrm{CdCl}_{2}\right)$ inhibitör etkisini azalttı̆ğ görülmüştür [24]. Benzer sonuçlar SNP $(50 \mu \mathrm{mol} / \mathrm{L})$ 'ye bağlı olarak, kadmiyum $(10,30,50,100,200$ ve $500 \mu \mathrm{mol} / \mathrm{L})$ stresi altındaki pirinç fidelerinde de tespit edilmiş̧ir. Ayrıca tohum çimlenmesi üzerinde de Cd'nin yol açtığı inhibitör etkiyi, SNP' nin azalttığ1 tespit edilmiş̧ir [25]. $0.2 \mathrm{mmol} / \mathrm{L} \mathrm{CdCl}_{2}$ ' ye maruz bırakılan pirinç fidelerine farklı $(0.05,0.1,0.2$ ve 0.4 
mmol/L) SNP konsantrasyonları uygulanmıştır. SNP muamelesi ile bitkideki MDA oranı azalmış ve konsantrasyon artışına paralel olarak GSH miktarındaki artışı inhibe edildiği rapor edilmiştir [26]. Ayçiçeği yapraklarında yapılan bir çalışmada NO' nun kadmiyum stresine karşı koruyucu rol oynadığ1 tespit edilmiştir. $100 \mu \mathrm{M}$ SNP uygulanan ayçiçeği fidelerinde GSH içeriği kontrole çok yakın olarak bulunmuştur. Aynı şekilde farklı konsantrasyonlarda SNP ve Cd uygulanan ayçiçeği fidelerinde GSH içeriğinde kontrole oranla çok az bir düşüş meydana geldiği görülmüştür [14]. Köpek dişi ayrığ1 (Cynodon dactylon) fidelerinde yapılan bir çalışmada; SNP' $\operatorname{nin}(250 \mu \mathrm{M}), \mathrm{Cd}(750 \mu \mathrm{M})$ toksisitesi üzerine etkileri araştırılmıştır. Yalnız SNP uygulanan fidelere kıyasla, SNP+ Cd uygulanan fidelerde taze ağılık ve GSH miktarı azalmıştır [27]. Yabani kimyon (Zygophyllum fabago) fidelerinde yapılan bir çalışmada, SA (salisilik asit) ve Pb (kurşun) uygulamasına bağlı olarak kontrole kıyasla; yalnız SA uygulanan fidelerde GSH azalmış, GSSG artmış, SA+Pb uygulanan fidelerde ise GSH azalmış, GSSG' de ise fark bulunamamıştır [28]. Salatalık (Cucumis sativus L.) fidelerinde yapılan bir çalışmada, SA ve Mn uygulamasına bağlı olarak kontrole kıyasla; yalnız SA uygulanan fidelerde hem GSH hem de GSSG miktarının arttığ $1, \mathrm{SA}+\mathrm{Mn}$ uygulanan fidelerde ise GSH' in azaldığı, GSSG' nin ise arttı̆̆ rapor edilmiş̧tir [29]. Arabidopsis thaliana fidelerinde yapılan başka bir çalışmada ise, Cd uygulanan fidelerde GSH ve GSSG içeriğinin kontrole göre, arttığı bildirilmiştir [30]. Kadmiyum toksisitesinin bezelye bitkisinde GSH ve GSSG miktarını kontrole göre azalttığını tespit etmişlerdir [31]. Lin ve arkadaşlarının yaptığı bir çalışmada ise, fidelerde Cd konsantrasyonları arttıkça kontrole göre; GSSG miktarının arttığı, GSH miktarının ise azaldığı tespit edilmiştir [32].

Biz bu çalışmada, önceden yapılmış araştırmaların ışı̆̆ında farklı Cd konsantrasyonlarının mısır (Zea Mays L. cv) fidelerinde yarattığı toksik etkiye karşı, SNP ön uygulamasının fizyolojik ve biyokimyasal bazı parametreler üzerinde hafifletici ya da teşvik edici etkilerini araştırmayı amaçladık.

\section{Materyal ve Metot}

\subsection{Bitki Materyaline Yapılan Uygulamalar}

Bu çalışmada kullanılan bitki materyali, Arzuman firmasına ait olup, tür adı haşlamalık mısır olarak geçen (Parti No: TR 42.1082.1102, Paketleme Tarihi: Ocak 2012) standart tohum etiketli mısır bitkisidir. Tamamen homojen olan mısır tohumları seçilerek saf su ile 1slatıldı ve karanlıkta 6 saat 23$25{ }^{\circ} \mathrm{C}$ 'de bekletildi. Bu sürenin sonunda tohumlar, hava alabilecekleri kapaklı çimlendirme kutularına dizilerek, 3 gün süreyle $23-25{ }^{\circ} \mathrm{C}$ 'de karanlıkta çimlenmeye bırakıldı. Daha sonra radikula uzunlukları eşit büyüklükte olan çimlenmiş tohumlar seçilerek (homojen) önceden belirli oranlarda hazırlanan kum (3/1) ve tarla toprağ 1 (3/2) karışımıyla doldurulmuş saksılara ekildi. Fideler uzun gün periyodunda (16/8), normal gün ışığında 15 günlük oluncaya kadar eşit miktarda musluk suyu ile haftada iki kez sulandı. Bu fidelerden, tamamen homojen büyüyen fideler seçilerek deney materyali olarak kullanıldı. 15 günlük mısır fideleri eşit sayıda fide içeren 3 gruba ayrıldı ve hidroponik ortam olarak 250 ml'lik koyu renk cam kaplar içinde bulunan saf su kullanıldı. Fidelerin köklerinden farklı konsantrasyonlarda $(25$ ve $50 \mu \mathrm{M})$ SNP, 2 gün boyunca uyguland. Daha sonra ayrı ayrı her bir grup, hazırlanan farklı $\mathrm{CdCl}_{2}$ konsantrasyonlarına $(25,50$ ve $75 \mu \mathrm{M}), 2$ gün boyunca hidroponik olarak maruz birakıldı.

\subsection{Redükte ve Okside Glutatyon (GSH ve GSSG) Analizi}

Mısır fidelerinin kök ve yapraklarında olmak üzere iki farklı dokuda çalışıldı. Bu amaçla bütün gruplar için ayrı ayrı eşit miktarda doku kullanıldı. 1'er g taze yaprak ve kök dokusu steril bir makasla parçalara bölünerek materyal olarak kullanıldı. Örnekler falkon tüplerine konuldu ve üzerine $10 \mathrm{ml}$ TRİS tampon çözeltisi (TRIS Baz, TRİS HCL, EDTA) eklenerek 4 dakikada homojenize edildi. Falkon tüplerinde olan karışımlar 6000-7000 rpm' de 10 dk santrifüj edildi. Bu süreç sonunda faz ayrımı oldu. Ayırdığımız üst fazlardan her bir örnekten $5 \mathrm{ml}$ cam deney tüplerine alındı. Ayırdığımız bu üst fazlardan her bir örnekten $5 \mathrm{ml}$ cam deney tüplerine alınd. Üzerine $1 \mathrm{ml} \%$ 10' luk perklorik asit eklenerek $5000 \mathrm{rpm}$ 'de 10 dk. santrifüj edildi. Daha sonra 1' er ml alınarak viallere konuldu. HPLC (Yüksek Performanslı Siv1 Kromatografisi)' de ölçüldü [33]. 


\subsection{Yă̆ Asidi (FA) Analizi}

Falkon tüplerinde olan karışımlar 6000-7000 rpm' de 10 dk. santrifüj edildi. Bu süreç sonunda faz ayrımı oldu. Üst faz ayrı bir tüpe alındı ve yağ asidi için alt fazda kalan falkon tüplerinde kalan pelet üzerine $10 \mathrm{ml}$ BHT' li hexan/izopropil alkol (3/2, v/v) eklendi ve homojenize edildi. Homojenizasyondan sonra numune 7000 rpm' de $10 \mathrm{dk}$. santrifüj edildi. Üst fazlar tüplere alındı. Sıvı üzerine \% 2'lik methanol sülfürik asitten $5 \mathrm{ml}$ örneklerin üzerine ilave edildi. Sonra bu örnekler $55{ }^{\circ} \mathrm{C}$ etüvde $12-15$ saat bekletildikten sonra etüvden çıkarılarak soğumaya bırakıldı. Soğuduktan sonra çıkarılan örneklerin üzerine $5 \mathrm{ml} \% 5$ ' lik NaCl (Sodyum Klorür) çözeltisi eklendi ve hemen ardından $5 \mathrm{ml} \mathrm{n}$-Hexan ilave edildi ve vorteksle karıştırıldı. Oda sıcaklığında 3-5 saat beklendi. Süre sonunda üst faz alındı, alt faz döküldü ve üst faz aynı deney tüpüne alındı ve üzerine $5 \mathrm{ml} \% 2$ ' lik $\mathrm{KHCO}_{3}$ (Potasyum bikarbonat) ilave edildi ve 2-3 saat oda sıcaklığında bekletildi. Süre sonunda üst faz küçük tüplere alındı ve alt faz döküldü ve örnekler $37-40{ }^{\circ} \mathrm{C}$ etüvde uçmaya bırakıldı. Uçma meydana geldikten sonra örnek kalıntılarının olduğu deney tüplerine $1 \mathrm{ml}$ heptan eklendi ve örnekler vortekslendikten sonra $1 \mathrm{ml}$ örnek viallere alınıp GC (Gaz Kromatografisi)' de analiz edildi [34, 35]. Yağ asidi miktarları ağırlığın \% değeri olarak verildi.

\section{4. İstatistik Analizler}

Çalışmamızdaki bütün parametreler 3 tekrarlı olarak analiz edildi. Verilerin doğruluk değerleri SPSS 15 paket programı kullanılarak ortalama ve One-way ANOVA ile test edildi. Gruplar arasındaki farklılıklar $\mathrm{p} \leq 0.05$ önemlilik seviyesinde ayırt edildi.

\section{Bulgular ve Tartışma}

\subsection{Bulgular}

\subsubsection{SNP ve Kadmiyum' un GSH Üzerine Etkisi}

Uygulama yapılan fidelerin köklerinde kontrol grubuna kıyasla; $25 \mu \mathrm{M}$ SNP, $50 \mu \mathrm{M}$ SNP, $25 \mu \mathrm{M}$ $\mathrm{SNP}+25 \mu \mathrm{M}$ Cd, $25 \mu \mathrm{M} \mathrm{SNP}+50 \mu \mathrm{M} \mathrm{Cd}, 25 \mu \mathrm{M} \mathrm{SNP}+75 \mu \mathrm{M}$ Cd, $50 \mu \mathrm{M} \mathrm{SNP}+25 \mu \mathrm{M}$ Cd, $50 \mu \mathrm{M}$ $\mathrm{SNP}+50 \mu \mathrm{M}$ Cd ve $50 \mu \mathrm{M} \mathrm{SNP}+75 \mu \mathrm{M}$ Cd gruplarında sirasiyla; $\% 35.14, \%$ 50.70, \% 10.42, \% 4.84, $\% 13.18, \%$ 9.83, \% 10.72 ve \% 17.57oranında azalma tespit edilmiştir $(\mathrm{P} \leq 0,05)$. Ayrıca $50 \mu \mathrm{M}$ Cd ve $75 \mu \mathrm{M}$ Cd gruplarında sırasıyla \% 11.09 ve \% 1.49 oranlarında artış tespit edilmiştir $(\mathrm{P} \leq 0,05)$. Gruplar arasında; $25 \mu \mathrm{M}$ Cd' ye göre $25 \mu \mathrm{M}$ SNP $+25 \mu \mathrm{M}$ Cd ve $50 \mu \mathrm{M} \mathrm{SNP}+25 \mu \mathrm{M}$ Cd gruplarında sirasiyla $\% 5.53$ ve \% 6.22 oranında artış; $50 \mu \mathrm{M}$ Cd' ye göre $25 \mu \mathrm{M} \mathrm{SNP}+50 \mu \mathrm{M}$ Cd ve $50 \mu \mathrm{M} \mathrm{SNP}+50 \mu \mathrm{M}$ Cd gruplarında sırasıyla \% 7.21 ve \% 0.58 oranında artış; $75 \mu \mathrm{M}$ Cd' ye göre $25 \mu \mathrm{M} \mathrm{SNP}+75 \mu \mathrm{M} \mathrm{Cd}$ ve $50 \mu \mathrm{M} \mathrm{SNP}+75 \mu \mathrm{M} \mathrm{Cd}$ grubunda sırasıyla $\% 7.07$ ve $\% 1.65$ oranında artış tespit edilmiştir $(\mathrm{P} \leq 0,05)$. Ayrıca uygulama yapılan köklerde, $25 \mu \mathrm{M}$ Cd grubundaki fark istatistiki açıdan anlamlı bulunmamıştır $(\mathrm{P}>0,05)$. Uygulama yapılan fidelerin yapraklarında kontrol grubuna kıyasla; $25 \mu \mathrm{M} \mathrm{SNP}+25 \mu \mathrm{M} \mathrm{Cd}$, $25 \mu \mathrm{M}$ SNP $+50 \mu \mathrm{M}$ Cd, $25 \mu \mathrm{M} \mathrm{SNP}+75 \mu \mathrm{M}$ Cd, $50 \mu \mathrm{M} \mathrm{SNP}+25 \mu \mathrm{M}$ Cd, $50 \mu \mathrm{M} \mathrm{SNP}+50 \mu \mathrm{M}$ Cd ve $50 \mu \mathrm{M}$ SNP+75 $\mu \mathrm{M}$ Cd gruplarinda sirasiyla \% 21.44, \% 17.12, \% 21.29, \% 22.38, \% 19.64 ve \% 21.76oranında azalma tespit edilmiştir $(\mathrm{P} \leq 0,05)$. Ayrıca $50 \mu \mathrm{M}$ Cd ve $75 \mu \mathrm{M}$ Cd gruplarında sırasıyla $\% 11.53 \mathrm{ve} \% 10.53$ oranında artış tespit edilmiştir $(\mathrm{P} \leq 0,05)$. Gruplar arasında; $25 \mu \mathrm{M}$ Cd' ye göre 25 $\mu \mathrm{M} \mathrm{SNP}+25 \mu \mathrm{M}$ Cd ve $50 \mu \mathrm{M} \mathrm{SNP}+25 \mu \mathrm{M}$ Cd gruplarında sırasıyla \% 5.60 ve $\% 4.33$ oranında artış tespit edilmiştir $(\mathrm{P} \leq 0,05)$ (Tablo 1). Ayrıca uygulama yapılan fidelerde, $25 \mu \mathrm{M} \mathrm{Cd}, 25 \mu \mathrm{M}$ SNP ve 50 $\mu \mathrm{M}$ SNP gruplarındaki farklar istatistiki açıdan anlamlı bulunamamıştır $(\mathrm{P}>0,05)$.

\subsubsection{SNP ve Kadmiyum'un GSSG Üzerine Etkisi}

Uygulama yapılan fidelerin köklerinde kontrole kıyasla; $75 \mu \mathrm{M} \mathrm{Cd}, 25 \mu \mathrm{M}$ SNP, $50 \mu \mathrm{M}$ SNP, $25 \mu \mathrm{M}$ $\mathrm{SNP}+25 \mu \mathrm{M} \mathrm{Cd}, 25 \mu \mathrm{M} \mathrm{SNP}+50 \mu \mathrm{M}$ Cd, $25 \mu \mathrm{M} \mathrm{SNP}+75 \mu \mathrm{M}$ Cd, $50 \mu \mathrm{M} \mathrm{SNP}+25 \mu \mathrm{M} \mathrm{Cd}, 50 \mu \mathrm{M}$ $\mathrm{SNP}+50 \mu \mathrm{M}$ Cd ve $50 \mu \mathrm{M} \mathrm{SNP}+75 \mu \mathrm{M}$ Cd gruplarinda sirasiyla; $\% 16.80, \%$ 9.61, \% 47.09, \% 33.97, $\% 43.32, \% 51.29, \% 49.07, \% 55.32$ ve \% 57.31 oranlarında azalma tespit edilmiştir $(\mathrm{P} \leq 0,05)$. Gruplar arasında; $25 \mu \mathrm{M}$ Cd' ye göre $25 \mu \mathrm{M} \mathrm{SNP}+25 \mu \mathrm{M} \mathrm{Cd}$ ve $50 \mu \mathrm{M} \mathrm{SNP}+25 \mu \mathrm{M}$ Cd grubunda sirasiyla $\%$ 
34.65 ve $\% 49.60$ oranında azalma; $50 \mu \mathrm{M}$ Cd' ye göre $25 \mu \mathrm{M}$ SNP+50 $\mu \mathrm{M}$ Cd ve $50 \mu \mathrm{M} \mathrm{SNP}+50 \mu \mathrm{M}$ Cd gruplarında sirasıyla \% 47.96 ve \% 58.98 oranında azalma; $75 \mu \mathrm{M}$ Cd' ye göre $25 \mu \mathrm{M}$ SNP+75 $\mu \mathrm{M}$ Cd ve $50 \mu \mathrm{M} \mathrm{SNP}+75 \mu \mathrm{M}$ Cd gruplarında sırasıyla $\% 41.46$ ve $\% 48.69$ oranında azalma tespit edilmiştir $(\mathrm{P} \leq 0,05)$. Ayrıca $25 \mu \mathrm{M} \mathrm{Cd}$ ve $50 \mu \mathrm{M}$ Cd gruplarında artış tespit edilse de istatistiki açıdan anlamlı bulunamamıştır $(\mathrm{P}>0.05)$. Uygulama yapılan fidelerin yapraklarında kontrole kıyasla; $25 \mu \mathrm{M}$ SNP, 50 $\mu \mathrm{M}$ SNP, $25 \mu \mathrm{M}$ SNP+ $25 \mu \mathrm{M}$ Cd, $25 \mu \mathrm{M}$ SNP+50 $\mu \mathrm{M}$ Cd, $25 \mu \mathrm{M} \mathrm{SNP}+75 \mu \mathrm{M}$ Cd ve $50 \mu \mathrm{M}$ SNP+75 $\mu \mathrm{M}$ Cd gruplarında sirasiyla; $\% 37.66, \% 33.17, \% 38.32, \% 38.49, \% 46.34$ ve $\% 28.46$ oranında azalma tespit edilmiştir $(\mathrm{P} \leq 0,05)$. Ayrıca $50 \mu \mathrm{M} \mathrm{Cd}$ ve $50 \mu \mathrm{M} \mathrm{SNP}+50 \mu \mathrm{M} \mathrm{Cd}$ gruplarında artış tespit edilmiştir $(\mathrm{P} \leq 0,05)$. Gruplar arasinda; $25 \mu \mathrm{M}$ Cd' ye göre $25 \mu \mathrm{M} \mathrm{SNP}+25 \mu \mathrm{M}$ Cd ve $50 \mu \mathrm{M} \mathrm{SNP}+25 \mu \mathrm{M} \mathrm{Cd}$ grubunda sirasiyla $\% 46.79$ ve $\% 25.88$ oranında azalma; $50 \mu \mathrm{M}$ Cd' ye göre $25 \mu \mathrm{M} \mathrm{SNP}+50 \mu \mathrm{M} \mathrm{Cd}$ grubunda \% 52.89 oranında azalma; $75 \mu \mathrm{M}$ Cd' ye göre $25 \mu \mathrm{M} \mathrm{SNP}+75 \mu \mathrm{M}$ Cd ve $50 \mu \mathrm{M}$ SNP+75 $\mu \mathrm{M}$ Cd gruplarında sırasıyla \% 40.26 ve \% 20.37 oranında azalma tespit edilmiştir $(\mathrm{P} \leq 0,05) .25 \mu \mathrm{M} \mathrm{Cd}, 75$ $\mu \mathrm{M}$ Cd ve $50 \mu \mathrm{M} \mathrm{SNP}+25 \mu \mathrm{M}$ Cd gruplarındaki farklar istatistiki açıdan anlamlı bulunmamıştır $(\mathrm{P}>0.05)$ (Tablo-1).

Tablo 1. SNP ön uygulamalı ve ön uygulamasız mısır (Zea mays L.) fidelerinde, kadmiyumun kök ve yaprakta GSH ve GSSG miktarları üzerine etkileri

\begin{tabular}{c|ccccc}
\hline \multirow{2}{*}{ GRUPLAR } & \multicolumn{2}{|c|}{ GSH $\left(\mu \mathrm{g} . \mathrm{g}^{-1} \mathrm{TA}\right)$} & \multicolumn{2}{c}{ GSSG $\left(\mu \mathrm{g} \cdot \mathrm{g}^{-1} \mathrm{TA}\right)$} \\
& KÖK & YAPRAK & KÖK & YAPRAK \\
\hline KONTROL & $13.43 \pm 0.43$ & $12.73 \pm 0.62$ & $115.85 \pm 7.48$ & $112.35 \pm 2.32$ \\
$25 \mu \mathrm{M} \mathrm{SNP}$ & $6.96 \pm 0.06^{*}$ & $7.90 \pm 0.84$ & $104.71 \pm 1.95^{*}$ & $70.04 \pm 9.37^{*}$ \\
$50 \mu \mathrm{M} \mathrm{SNP}$ & $5.29 \pm 0.04^{*}$ & $8.01 \pm 0.94$ & $61.31 \pm 0.90^{*}$ & $75.08 \pm 6.51^{*}$ \\
$25 \mu \mathrm{M} \mathrm{Cd}$ & $11.40 \pm 0.60$ & $9.47 \pm 0.61$ & $117.07 \pm 7.86$ & $130.22 \pm 8.36$ \\
$50 \mu \mathrm{M} \mathrm{Cd}$ & $11.92 \pm 0.59^{*}$ & $10.06 \pm 0.14^{*}$ & $126.20 \pm 6.47$ & $146.65 \pm 10.20^{*}$ \\
$75 \mu \mathrm{M} \mathrm{Cd}$ & $10.89 \pm 0.12^{*}$ & $9.97 \pm 0.08^{*}$ & $96.39 \pm 2.05^{*}$ & $100.93 \pm 3.44$ \\
$25 \mu \mathrm{M} \mathrm{SNP} \mathrm{-} \mathrm{25} \mathrm{Cd}$ & $12.03 \pm 0.1 * \square$ & $9.97 \pm 0.08^{*}$ & $76.51 \pm 1.88^{*} \square$ & $69.30 \pm 6.75^{* \square}$ \\
$25 \mu \mathrm{M} \mathrm{SNP} \mathrm{-} \mathrm{50} \mathrm{Cd}$ & $12.78 \pm 0.72^{* \square}$ & $10.55 \pm 0.18^{*}$ & $65.67 \pm 1.21^{* \square}$ & $69.12 \pm 0.77^{* \square}$ \\
$25 \mu \mathrm{M} \mathrm{SNP} \mathrm{-} \mathrm{75} \mathrm{Cd}$ & $11.66 \pm 0.02^{* \square}$ & $10.02 \pm 0.19^{*}$ & $56.43 \pm 0.20^{* \square}$ & $60.29 \pm 1.97^{* \square}$ \\
$50 \mu \mathrm{M} \mathrm{SNP} \mathrm{-} \mathrm{25} \mathrm{Cd}$ & $12.11 \pm 0.08^{* \square}$ & $9.88 \pm 0.41^{* \square}$ & $59 \pm 0.21^{\square}$ & $96.52 \pm 3.44^{* \square}$ \\
$50 \mu \mathrm{M} \mathrm{SNP} \mathrm{-} \mathrm{50} \mathrm{Cd}$ & $11.99 \pm 0.07^{* \square}$ & $10.23 \pm 0.42^{*}$ & $51.76 \pm 0.48^{*}$ & $131.68 \pm 9.63^{*}$ \\
$50 \mu \mathrm{M} \mathrm{SNP} \mathrm{-} \mathrm{75} \mathrm{Cd}$ & $11.07 \pm 0.03^{* \square}$ & $9.96 \pm 0.11^{*}$ & $49.47 \pm 0.28^{* \square}$ & $80.38 \pm 2.50^{* \square}$ \\
\hline
\end{tabular}

*:Kontrole kıyasla ${ }^{\square}$ : Gruplar arası; $\mathrm{p} \leq 0.05$ olasılık seviyelerinde önemli. Verilerin ortalaması \pm SE (n: 3)

\subsubsection{SNP ve Kadmiyum' un Yağ Asitleri Üzerine Etkisi}

\subsubsection{Palmitik asit (16:0)}

Uygulama yapılan fidelerin köklerinde kontrol grubuna kıyasla; $75 \mu \mathrm{M} \mathrm{Cd}, 25 \mu \mathrm{M} \mathrm{SNP}, 25 \mu \mathrm{M} \mathrm{SNP}+50$ $\mu \mathrm{M} \mathrm{Cd}, 25 \mu \mathrm{M}$ SNP+75 $\mu \mathrm{M}$ Cd ve $50 \mu \mathrm{M} \mathrm{SNP}+50 \mu \mathrm{M}$ Cd gruplarında sirasiyla $\% 25.91, \% 30.08, \%$ 28.64, \% 24.78 ve \% 61.55 oranında artış tespit edilmiştir $(\mathrm{P} \leq 0,05)$. Gruplar arasında; $50 \mu \mathrm{M}$ Cd' ye göre $50 \mu \mathrm{M} \mathrm{SNP}+50 \mu \mathrm{M} \mathrm{Cd}$ grubunda $\% 36.38$ oranında artış tespit edilmiştir $(\mathrm{P} \leq 0,05)$. Ayrıca $25 \mu \mathrm{M}$ $\mathrm{Cd}, 50 \mu \mathrm{M} \mathrm{Cd}, 50 \mu \mathrm{M}$ SNP, $25 \mu \mathrm{M} \mathrm{SNP}+25 \mu \mathrm{M} \mathrm{Cd}, 50 \mu \mathrm{M} \mathrm{SNP}+25 \mu \mathrm{M}$ Cd ve $50 \mu \mathrm{M} \mathrm{SNP}+75 \mu \mathrm{M}$ $\mathrm{Cd}$ gruplarındaki farklar istatistiki açıdan anlamlı bulunamamıştır $(\mathrm{P}>0,05)$. Uygulama yapılan fidelerin yapraklarında kontrol grubuna kiyasla; $25 \mu \mathrm{M} \mathrm{Cd}, 50 \mu \mathrm{M} \mathrm{Cd}, 75 \mu \mathrm{M} \mathrm{Cd}, 25 \mu \mathrm{M}$ SNP, $25 \mu \mathrm{M}$ SNP +25 $\mu \mathrm{M}$ Cd, $25 \mu \mathrm{M}$ SNP+75 $\mu \mathrm{M}$ Cd ve $50 \mu \mathrm{M}$ SNP+50 $\mu \mathrm{M}$ Cdgruplarinda sirasiyla $\% 21.77, \% 24.32, \%$ $31.04, \% 15.13, \% 25.64, \% 24.86$ ve \% 13.90 oranında artış tespit edilmiştir ( $\mathrm{P} \leq 0,05)$. Gruplar arasında; $25 \mu \mathrm{M}$ Cd'ye göre $50 \mu \mathrm{M} \mathrm{SNP}+25 \mu \mathrm{M}$ Cd grubunda $\% 14.20$ azalma; $50 \mu \mathrm{M}$ Cd' ye göre $25 \mu \mathrm{M}$ $\mathrm{SNP}+50 \mu \mathrm{M}$ Cd ve $50 \mu \mathrm{M} \mathrm{SNP}+50 \mu \mathrm{M}$ Cd gruplarında sirasiyla $\% 12.92$ ve $\% 8.38$ oranında azalma; 
$75 \mu \mathrm{M}$ Cd' ye göre $50 \mu \mathrm{M} \mathrm{SNP}+75 \mu \mathrm{M} \mathrm{Cd}$ grubunda $\% 17.44$ azalma tespit edilmiştir $(\mathrm{P} \leq 0,05)$. Ayrıca $50 \mu \mathrm{M}$ SNP, $25 \mu \mathrm{M} \mathrm{SNP}+50 \mu \mathrm{M} \mathrm{Cd}, 50 \mu \mathrm{M} \mathrm{SNP}+25 \mu \mathrm{M}$ Cd ve $50 \mu \mathrm{M} \mathrm{SNP}+75 \mu \mathrm{M}$ Cd gruplarındaki farklar istatistiki açıdan anlamlı bulunamamıştır $(\mathrm{P}>0,05)$ (Tablo 2-A).

\subsubsection{Palmioleik asit (16:1)}

Uygulama yapılan fidelerin yapraklarında kontrol grubuna kıyasla; $75 \mu \mathrm{M} \mathrm{Cd}, 25 \mu \mathrm{M}$ SNP ve $50 \mu \mathrm{M}$ $\mathrm{SNP}+50 \mu \mathrm{M}$ Cdgruplarında sırasıyla \% 14.76, \% 18.33 ve \% 11.55 oranında artış; $50 \mu \mathrm{M}$ SNP+75 $\mu \mathrm{M}$ $\mathrm{Cd}$ grubunda ise \% 15.30 oranında azalma tespit edilmiştir $(\mathrm{P} \leq 0,05)$. Gruplar arasında; $50 \mu \mathrm{M}$ Cd' ye göre $25 \mu \mathrm{M}$ SNP $+50 \mu \mathrm{M}$ Cd grubunda $\% 9.87$ oranında azalma; $75 \mu \mathrm{M}$ Cd' ye göre $25 \mu \mathrm{M} \mathrm{SNP}+75$ $\mu \mathrm{M}$ Cd ve $50 \mu \mathrm{M} \mathrm{SNP}+75 \mu \mathrm{M}$ Cd gruplarında sirasiyla \% 18.21 ve $\% 26.20$ oranında azalma tespit edilmiştir $(\mathrm{P} \leq 0,05)$. Ayrıca $25 \mu \mathrm{M} \mathrm{Cd}, 50 \mu \mathrm{M} \mathrm{Cd}, 50 \mu \mathrm{M} \mathrm{SNP}, 25 \mu \mathrm{M} \mathrm{SNP}+25 \mu \mathrm{M} \mathrm{Cd}, 25 \mu \mathrm{M} \mathrm{SNP}+50$ $\mu \mathrm{M} \mathrm{Cd}, 25 \mu \mathrm{M} \mathrm{SNP}+75 \mu \mathrm{M}$ Cd ve $50 \mu \mathrm{M} \mathrm{SNP}+25 \mu \mathrm{M}$ Cd gruplarındaki farklar istatistiki açıdan anlamlı bulunamamışırı $(\mathrm{P}>0,05)$. Uygulama yapılan fidelerin köklerinde yapılan analizlerde 16:1 yă asidine rastlanmamıştır (Tablo 2-A).

Tablo 2-A. SNP ön uygulamalı ve ön uygulamasız mısır (Zea mays L.) fidelerinde, kadmiyumun kökte yağ asidi bileşiminin (\%) değişimi üzerine etkileri

\begin{tabular}{c|cc|cc|cc}
\hline \multirow{2}{*}{ GRUPLAR } & \multicolumn{5}{c}{ Yağ asidi bileşiminin (\%) değişimi üzerine etkileri } \\
\cline { 2 - 7 } & \multicolumn{2}{c}{$16: 00$} & & $16: 01$ & \multicolumn{2}{c}{$18: 00$} \\
& KÖK & YAPRAK & KÖK & YAPRAK & KÖK & YAPRAK \\
\hline KONTROL & $36.20 \pm 3.76$ & $12.95 \pm 0.40$ & - & $10.92 \pm 0.45$ & $30.13 \pm 3.08$ & - \\
$25 \mu \mathrm{M}$ SNP & $47.09 \pm 2.30^{*}$ & $14.92 \pm 0.09^{*}$ & - & $12.91 \pm 0.33^{*}$ & - & - \\
$50 \mu \mathrm{M}$ SNP & $39.67 \pm 1.54$ & $12.52 \pm 0.00$ & - & $11.84 \pm 0.00$ & $39.79 \pm 3.86^{*}$ & - \\
$25 \mu \mathrm{M} \mathrm{Cd}$ & $39.92 \pm 1.92$ & $15.77 \pm 0.46^{*}$ & - & $10.88 \pm 0.06$ & $40.07 \pm 2.23^{*}$ & - \\
$50 \mu \mathrm{M}$ Cd & $42.88 \pm 1.76$ & $16.10 \pm 0.06^{*}$ & - & $11.75 \pm 0.31$ & $54.53 \pm 0.48^{*}$ & - \\
$75 \mu \mathrm{M}$ Cd & $45.57 \pm 1.55^{*}$ & $16.98 \pm 0.54^{*}$ & - & $12.52 \pm 0.18^{*}$ & $54.79 \pm 1.32^{*}$ & - \\
$25 \mu \mathrm{M}$ SNP - 25 Cd & $40.67 \pm 2.07$ & $16.28 \pm 0.42^{*}$ & - & $11.41 \pm 0.58$ & $33.85 \pm 0.35$ & - \\
$25 \mu \mathrm{M}$ SNP - 50 Cd & $46.57 \pm 2.35^{*}$ & $14.02 \pm 0.20^{\square}$ & - & $10.59 \pm 0.63^{\square}$ & $32.93 \pm 5.42^{\square}$ & - \\
$25 \mu \mathrm{M}$ SNP - 75 Cd & $45.17 \pm 5.69^{*}$ & $16.17 \pm 0.13^{*}$ & - & $10.24 \pm 0.14^{\square}$ & $16.36 \pm 1.62^{*} \square$ & - \\
$50 \mu \mathrm{M}$ SNP - 25 Cd & $32.84 \pm 2.76$ & $13.53 \pm 0.13^{\square}$ & - & $11.03 \pm 0.07$ & $28.63 \pm 3.47^{\square}$ & - \\
$50 \mu \mathrm{M}$ SNP - 50 Cd & $58.48 \pm 5.00^{*}$ & $14.75 \pm 0.04^{*}$ & - & $12.18 \pm 0.38^{*}$ & - & - \\
$50 \mu \mathrm{M}$ SNP - 75 Cd & $44.67 \pm 2.71$ & $14.01 \pm 0.94^{\square}$ & - & $9.24 \pm 0.36^{* \square}$ & - & - \\
\hline
\end{tabular}

$*:$ Kontrole kıyasla ${ }^{\square}$ : Gruplar arası; $\mathrm{p} \leq 0.05$ olasılık seviyelerinde önemli. Verilerin ortalaması \pm SE (n: 3 )

\subsubsection{Stearik asit (18:0)}

Uygulama yapılan fidelerin köklerinde kontrol grubuna kıyasla; $25 \mu \mathrm{M} \mathrm{Cd}, 50 \mu \mathrm{M} \mathrm{Cd}, 75 \mu \mathrm{M} \mathrm{Cd}$ ve 50 $\mu$ M SNP gruplarında sırasıyla \% 32.99, \% 80.98 ve $\% 81.84$ oranlarında artış tespit edilmiştir $(\mathrm{P} \leq 0,05)$. Ayrıca $25 \mu \mathrm{M}$ SNP+75 $\mu \mathrm{M}$ Cd grubunda $\% 45.70$ oranında azalma tespit edilmiştir $(\mathrm{P} \leq 0,05)$. Gruplar arasında; $25 \mu \mathrm{M}$ Cd'ye göre $50 \mu \mathrm{M} \mathrm{SNP}+25 \mu \mathrm{M}$ Cd grubunda \% 28.55 oranında azalma; $50 \mu \mathrm{M}$ Cd' ye göre $25 \mu \mathrm{M} \mathrm{SNP}+50 \mu \mathrm{M}$ Cd grubunda $\% 39.61$ oranında azalma; $75 \mu \mathrm{M}$ Cd' ye göre $25 \mu \mathrm{M} \mathrm{SNP}+75$ $\mu \mathrm{M}$ Cd grubunda $\% 70.14$ oranında azalma tespit edilmiştir $(\mathrm{P} \leq 0,05) .25 \mu \mathrm{M} \mathrm{SNP}, 25 \mu \mathrm{M} \mathrm{SNP}+25 \mu \mathrm{M}$ $\mathrm{Cd}, 25 \mu \mathrm{M} \mathrm{SNP}+50 \mu \mathrm{M}$ Cd ve $50 \mu \mathrm{M} \mathrm{SNP}+25 \mu \mathrm{M}$ Cd gruplarındaki farklar istatistiki açıdan anlamlı bulunamamıştır $(\mathrm{P}>0,05)$. Uygulama yapılan fidelerin yapraklarında, yapılan analizlerde 18:0 yăg asidine rastlanmamıştır (Tablo 2-A).

\subsubsection{Linoleik asit (18:2)}

Uygulama yapılan fidelerin köklerinde kontrol grubuna kıyasla; $50 \mu \mathrm{M} \mathrm{Cd}, 75 \mu \mathrm{M} \mathrm{Cd}, 25 \mu \mathrm{M} \mathrm{SNP}+25$ $\mu \mathrm{M} \mathrm{Cd}, 25 \mu \mathrm{M} \mathrm{SNP}+50 \mu \mathrm{M} \mathrm{Cd}, 25 \mu \mathrm{M} \mathrm{SNP}+75 \mu \mathrm{M}$ Cd ve $50 \mu \mathrm{M} \mathrm{SNP}+50 \mu \mathrm{M}$ Cd gruplarinda sirasiyla $\%$ 56.36, \% 60.85, \% 99.62, \% 73.49, \% 85.15 ve \% 99.92oranlarında artış tespit edilmiştir $(\mathrm{P} \leq 0,05)$. Gruplar arasında; $25 \mu \mathrm{M}$ Cd'ye göre $25 \mu \mathrm{M} \mathrm{SNP}+25 \mu \mathrm{M}$ Cd grubunda $\% 61.89$ oranında artı̧̧; $50 \mu \mathrm{M}$ 
Cd' ye göre $50 \mu \mathrm{M} \mathrm{SNP}+50 \mu \mathrm{M}$ Cd grubunda \% 27.86 oranında artış; $75 \mu \mathrm{M}$ Cd' ye göre $25 \mu \mathrm{M}$ $\mathrm{SNP}+75 \mu \mathrm{M}$ Cd grubunda \% 15.10 oranında artış tespit edilmiştir $(\mathrm{P} \leq 0,05)$. Ayrıca $50 \mu \mathrm{M}$ SNP, $25 \mu \mathrm{M}$ $\mathrm{Cd}$ ve $50 \mu \mathrm{M}$ SNP$+25 \mu \mathrm{M}$ Cd gruplarındaki farklar istatistiki açıdan anlamlı bulunamamıştır $(\mathrm{P}>0,05)$. Uygulama yapılan fidelerin yapraklarında kontrol grubuna kıyasla; $25 \mu \mathrm{M} \mathrm{Cd}, 50 \mu \mathrm{M} \mathrm{Cd}, 75 \mu \mathrm{M} \mathrm{Cd}$, $25 \mu \mathrm{M}$ SNP, $25 \mu \mathrm{M} \mathrm{SNP}+25 \mu \mathrm{M} \mathrm{Cd}, 25 \mu \mathrm{M} \mathrm{SNP}+50 \mu \mathrm{M} \mathrm{Cd}, 25 \mu \mathrm{M} \mathrm{SNP}+75 \mu \mathrm{M} \mathrm{Cd}, 50 \mu \mathrm{M} \mathrm{SNP}+25$ $\mu \mathrm{M} \mathrm{Cd}, 50 \mu \mathrm{M} \mathrm{SNP}+50 \mu \mathrm{M}$ Cd ve $50 \mu \mathrm{M}$ SNP+75 $\mu \mathrm{M}$ Cd gruplarında sirasiyla $\% 24.66, \% 34.07, \%$ 44.61, \% 14.25, \% 10.90, \% 17.22, \% 40.02, \% 14.12, \% 10.04 ve \% 54.64 oranında artış tespit edilmiştir $(\mathrm{P} \leq 0,05)$. Ayrıca $50 \mu \mathrm{M}$ SNP grubunda \% 7.31 oranında azalma tespit edilmiştir $(\mathrm{P} \leq 0,05)$. Gruplar arasinda; $25 \mu \mathrm{M}$ Cd'ye göre $25 \mu \mathrm{M} \mathrm{SNP}+25 \mu \mathrm{M}$ Cd ve $50 \mu \mathrm{M} \mathrm{SNP}+25 \mu \mathrm{M}$ Cd grubunda sirasiyla \% 11.03 ve $\% 8.45$ oranında azalma; $50 \mu \mathrm{M}$ Cd' ye göre $25 \mu \mathrm{M} \mathrm{SNP}+50 \mu \mathrm{M}$ Cd ve $50 \mu \mathrm{M}$ SNP+50 $\mu \mathrm{M}$ Cd grubunda sirasılyla \% 12.57 ve \% 17.93 oranında azalma; $75 \mu \mathrm{M}$ Cd' ye göre $50 \mu \mathrm{M} \mathrm{SNP}+75 \mu \mathrm{M}$ Cd grubunda \% 6.95 oranında artış tespit edilmiştir $(\mathrm{P} \leq 0,05)$ (Tablo 2-B).

\subsubsection{Linolenik asit (18:3)}

Uygulama yapılan fidelerin yapraklarında kontrol grubuna kıyasla; $50 \mu \mathrm{M} \mathrm{Cd}, 75 \mu \mathrm{M}$ Cd ve $25 \mu \mathrm{M}$ SNP gruplarında sirasiyla\% $13.13, \% 16.83$ ve $\% 12.80$ oranında azalma ve $50 \mu \mathrm{M} \mathrm{SNP}+25 \mu \mathrm{M} \mathrm{Cd}$ grubunda\% 9.13 oranında artış tespit edilmiştir $(\mathrm{P} \leq 0,05)$. Gruplar arasında; $25 \mu \mathrm{M}$ Cd'ye göre $50 \mu \mathrm{M}$ $\mathrm{SNP}+25 \mu \mathrm{M}$ Cd grubunda $\% 15.68$ oranında artış; $50 \mu \mathrm{M}$ Cd' ye göre $25 \mu \mathrm{M} \mathrm{SNP}+50 \mu \mathrm{M}$ Cd ve 50 $\mu \mathrm{M}$ SNP $+50 \mu \mathrm{M}$ Cd grubunda sirasıyla \% 21.29 ve \% 16.73 oranında artış; $75 \mu \mathrm{M}$ Cd' ye göre $25 \mu \mathrm{M}$ $\mathrm{SNP}+75 \mu \mathrm{M}$ Cd ve $50 \mu \mathrm{M}$ SNP $+75 \mu \mathrm{M}$ Cd grubunda sırasıyla $\% 23.83$ ve $\% 23.93$ oranında artış tespit edilmiştir $(\mathrm{P} \leq 0,05)$ (Tablo 2-B). Ayrıca $25 \mu \mathrm{M} \mathrm{Cd}, 50 \mu \mathrm{M}$ SNP, $25 \mu \mathrm{M} \mathrm{SNP}+25 \mu \mathrm{M} \mathrm{Cd}, 25 \mu \mathrm{M}$ $\mathrm{SNP}+50 \mu \mathrm{M} \mathrm{Cd}, 25 \mu \mathrm{M} \mathrm{SNP}+75 \mu \mathrm{M} \mathrm{Cd}, 50 \mu \mathrm{M} \mathrm{SNP}+50 \mu \mathrm{M}$ Cd ve $50 \mu \mathrm{M} \mathrm{SNP}+75 \mu \mathrm{M} \mathrm{Cd}$ gruplarındaki farklar istatistiki açıdan anlamlı bulunamamıştır $(\mathrm{P}>0,05)$. Uygulama yapılan fidelerin köklerinde, yapılan analizlerde 18:3 yağ asidine rastlanmamıştır.

Tablo 2-B. SNP ön uygulamalı ve ön uygulamasız mısır (Zea mays L.) fidelerinde, kadmiyumun kökte yağ asidi bileşiminin (\%) değişimi üzerine etkileri

\begin{tabular}{|c|c|c|c|c|}
\hline \multirow{3}{*}{ GRUPLAR } & \multicolumn{4}{|c|}{ Yağ asidi bileşiminin (\%) değişimi üzerine etkileri } \\
\hline & \multicolumn{2}{|c|}{ 18:02 } & \multicolumn{2}{|c|}{ 18:03 } \\
\hline & KÖK & YAPRAK & KÖK & YAPRAK \\
\hline KONTROL & $13.13 \pm 2.80$ & $8.08 \pm 0.10^{*}$ & - & $60.56 \pm 1.35$ \\
\hline $25 \mu \mathrm{M} \mathrm{SNP}$ & - & $9.22 \pm 0.01 *$ & - & $52.81 \pm 1.53 *$ \\
\hline $50 \mu \mathrm{M}$ SNP & $17.18 \pm 1.74$ & $7.48 \pm 0.00^{*}$ & - & $60.98 \pm 0.00$ \\
\hline $25 \mu \mathrm{M} \mathrm{Cd}$ & $16.19 \pm 1.26$ & $10.06 \pm 0.11 *$ & - & $57.13 \pm 1.82$ \\
\hline $50 \mu \mathrm{M} \mathrm{Cd}$ & $20.53 \pm 1.49 *$ & $10.83 \pm 0.11 *$ & - & $52.61 \pm 1.61 *$ \\
\hline $75 \mu \mathrm{M} \mathrm{Cd}$ & $21.12 \pm 2.55^{*}$ & $11.67 \pm 0.26^{*}$ & - & $50.36 \pm 0.35^{*}$ \\
\hline $25 \mu \mathrm{M}$ SNP - $25 \mathrm{Cd}$ & $26.21 \pm 2.49 * \square$ & $8.96 \pm 0.23^{* \square}$ & - & $58.68 \pm 2.81$ \\
\hline $25 \mu \mathrm{M}$ SNP - $50 \mathrm{Cd}$ & $22.78 \pm 2.76^{*}$ & $9.46 \pm 0.24^{* \square}$ & - & $63.80 \pm 1.80^{\square}$ \\
\hline $25 \mu \mathrm{M}$ SNP - $75 \mathrm{Cd}$ & $24.31 \pm 0.63 * \square$ & $11.30 \pm 0.09 *$ & - & $62.26 \pm 0.10^{\square}$ \\
\hline $50 \mu \mathrm{M}$ SNP $-25 \mathrm{Cd}$ & $14.45 \pm 2.28$ & $9.21 \pm 0.18^{* \square}$ & - & $66.08 \pm 0.39 * \square$ \\
\hline $50 \mu \mathrm{M}$ SNP $-50 \mathrm{Cd}$ & $26.25 \pm 0.40^{* \square}$ & $8.88 \pm 0.12^{* \square}$ & - & $61.41 \pm 0.49^{\square}$ \\
\hline $50 \mu \mathrm{M}$ SNP $-75 \mathrm{Cd}$ & - & $12.49 \pm 0.47^{* \square}$ & - & $62.41 \pm 0.11^{\square}$ \\
\hline
\end{tabular}

\subsection{Tartışma}

Genel anlamda Cd uygulanan mısır fidelerinin köklerinde ve yapraklarında SNP ön uygulamasız [36], [37], [38] fidelerde, kontrole kıyasla redükte glutatyon değerlerinde artma; SNP ön uygulamalı [14], [26], [27] fidelerde ise azalma tespit edildi. Bu konuda $50 \mu \mathrm{M}$ SNP ön uygulamasının hem kökte hemde yaprakta Cd' nin GSH üzerindeki arttırıcı etkisini hafifletme çabası anlamlı bulunmuştur [39], [40], [22]. Tek başına SNP uygulamalarında, redükte glutatyon miktarı üzerinde kontrole kıyasla,50 $\mu$ M SNP daha azaltıcı bulunmuştur. Genel anlamda, Cd uygulanan mısır fidelerinin köklerinde ve yapraklarında SNP ön uygulamasız [41], [32], [42] fidelerde, kontrole kıyasla okside glutatyon değerlerinde artma ve SNP ön uygulamalı [29], [28] fidelerde ise azalma tespit edildi. Bu konuda SNP ön uygulamasının hem kökte (50 $\mu \mathrm{M}$ SNP) hem de yaprakta (25 $\mu \mathrm{M}$ SNP), Cd' nin GSSG miktarı üzerindeki arttırıcı etkisini 
hafifletme çabası anlamlı bulunmuştur. Tek başına SNP uygulamalarında, GSSG miktarı üzerinde kontrole kıyasla, $25 \mu \mathrm{M}$ SNP daha azaltıcı bulunmuştur. NO, etilenin senesens-arttırıcı etkilerine karşı müdahale eder ve PAS' nin katılımının başka bir ilgi alanı olduğu ABA' da yer almaktadır. PAS, NO arasındaki çoğu durumların hormonlar ile bağlantılı olduğu düşünülmektedir [23]. Yağ asitlerini mısır üzerinde veya başka bir bitki üzerinde SNP ile Cd' ye bağlı olarak çalışan bir makaleye rastlamadık. Bu nedenle tartışmamızı çok derinleştirmeden stresi hafifleten bir haberci molekül olan salisilik asit üzerinden ele alacağız. Farklı bitkilerde Cd' nin yol açtığı toksik stres veya oksidatif stresin fidelerin yapraklarındaki membranlarda yağ asidi profilini etkilediği bildirilmiştir [43], [44]. Genel olarak fidelere uygulanan kadmiyum konsantrasyonları arttıkça, hem SNP ön uygulamasız [45], [46], [47] hem de SNP ön uygulamalı [46], fidelerde kontrol grubu fidelerine kıyasla 16:0 yaprak ve köklerde artmıştır. Bu konuda SNP ön uygulamasının (50 $\mu \mathrm{M}$ SNP), Cd' nin palmitik asit miktarı üzerindeki arttırıcı etkisini hafifletme çabası anlamlı bulunmuştur [46]. Tek başına SNP uygulamalarında, palmitik asit üzerinde kontrole kıyasla, $50 \mu \mathrm{M}$ SNP daha az bulunmuştur. Cd uygulamaları ile SNP ön uygulamasız [45] ve SNP ön uygulamalı fidelerde; 16:1 yapraklarda genel olarak artarken, bazı gruplarda SNP ön uygulamasıyla bu artış hafifletilmiştir. Bu konuda SNP ön uygulamasının (50 $\mu \mathrm{M} \mathrm{SNP})$, Cd' nin 16:1 üzerindeki arttırıcı etkisini hafifletme çabası anlamlı bulunmuştur [45]. Cd uygulamaları ile SNP ön uygulamasız [45], [46], [47] ve SNP ön uygulamalı [39] fidelerde 18:0 köklerde artmıştır. Bu konuda SNP ön uygulamasının (50 $\mu \mathrm{M}$ SNP), Cd' nin 18:0 üzerindeki arttırıcı etkisini hafifletme çabası anlamlı bulunmuştur [46]. Cd uygulamaları ile SNP ön uygulaması [45], [48], [47] ve SNP ön uygulamalı fidelerde 18:2 köklerde ve yapraklarda artış tespit edilmiştir. Bu konuda SNP ön uygulamasının (50 $\mu \mathrm{M}$ SNP), Cd' nin 18:2 miktarı üzerindeki arttırıcı etkisini hafifletme çabası anlamlı bulunmuştur [46]. Cd uygulamaları ile SNP ön uygulamasız [45], [46], [48] fidelerde 18:3 yaprakta azalırken; SNP ön uygulamalı [46] bazı fidelerde ise 18:3 miktarı yapraklarda artmıştır. Bu konuda SNP ön uygulamasının (25 $\mu$ M SNP), Cd' nin 18:3 miktarı üzerindeki arttırıcı etkisini hafifletme çabası anlamlı bulunmuştur [46]. Kontrole kiyasla, yaprakta 16:0, 18:2, 18:3 yă asitleri artarken; 16:1' de azalma meydana gelmiştir. Kökte, $16: 1$ ve $18: 3^{\prime}$ e rastlanmamıştır. Yapraklarda ise 18:0' a rastlanmamıştır. Diğer yağ asitleri için de benzer sonuçlar tespit edilmiştir.

\section{Sonuç ve Öneriler}

Elde edilen bulgulara göre, düşük $\mathrm{Cd}$ konsatrasyonlarının dahi mısır fideleri üzerinde negatif etkilerinin olduğu tespit edildi. SNP' nin doza bağlı olarak Cd' ye karşı hafifletici etki yarattığı bulundu. Sonuç olarak elde edilen veriler; seçilen konsantrasyonlara, planlanan uygulama şekline ve süresine bağlı olarak mısır fidelerinde SNP' nin, Cd' nin belirli parametreler üzerinde sebep olduğu oksidatif stresi sınırlı ölçüde de olsa düzenleyebildiğini düşündürmektedir. Literatür taramalarımızda mısır bitkisinde, SNP ve Cd'yi birlikte çalışan bir makaleye rastlamadığımız için parametreleri çoğunlukla dolaylı makaleler üzerinden tartışmaya çalışıldı. Ancak konunun tam anlaşılması açısından, enzimatik olan ve olmayan antioksidan temizleyici unsurların da çalışılmasının çalışmamıza katkı sağlayacağı kanaatindeyiz.

\section{Teşekkür}

Bu proje çalışmasında bize maddi destek sağlayan FÜBAP'a, bilgi ve teknik imkânlarını bize sunan Prof. Dr. Ökkeş YILMAZ hocamıza teşekkür ederiz.

\section{Kaynaklar}

[1] Ruis-Jiménez J., Luque-Garcia J.L., Luque de Castro M.D. 2003. Dynamic ultrasound-assisted extraction of cadmium and lead from plants prior to electrothermal atomic absoption spectrometry. Anal. Chim. Acta, 480: 231-237.

[2] Ayhan B. 2006. Mısır (Zea mays L.)'ın Bazı Çeşitlerinde Ağır Metal (Cd, Pb) Stresinin Etkilerinin Belirlenmesi. Hacettepe Üniversitesi Fen Bilimleri Enstitüsü, Yüksek Lisans Tezi, Ankara.

[3] Öktüren Asri F., Sönmez S., Çıtak S. 2007. Kadmiyumun çevre ve insan sağlığı üzerine etkileri, Dergi Park Akademik, 24 (1): 32-39. 
[4] Durner J., Klessig D.F. 1999. Nitric Oxide as a Signal in Plants, Current Opinion in Plant Biology, 2: 369-374.

[5] Neill S.J., Desikan R., Clarke A., Hancock J.T. 2002a. Nitric Oxide is a Novel Component of Absisic Acid Signalling in Stomatal Guard Cell. Plant Physiology, 128: 13-16.

[6] Leshem Y.Y., Haramaty E. 1996. The Characterisation and Contrasting Effects of the Nitric Oxide Free Radical in Vegetative Stress and Senescence of Pisum sativum L. Foliage, Journal of Plant Physiology, 148: 258-263.

[7] Stöhr C., Ullrich W.R. 2002. Generation and Possible Roles of NO in Plant Roots and Their Apoplastic Space. Journal of Experimental Botany, 53 (379): 2293-2303.

[8] Selçukcan Ç. 2005. Ayçiçeği (Helianthus annuus L.) bitkisinde senesens ile nitrik oksit arasındaki ilişkinin incelenmesi. Yüksek Lisans Tezi, İstanbul Üniversitesi Fen Bilimleri Enstitüsü, İstanbul.

[9] Okçu M., Tozlu E., Kumlay A.M., Pehluvan M. 2009. Ağır Metallerin Bitkiler Üzerine Etkileri, Alınteri Dergisi, 17 (B), 14- 26, ISSN: 1307-3311.

[10] Sonsuz B., Kargığlu A.F., Şıpka M., Oruç M.M., Hepşen Ö., Selvi E., Mustak H., Kargı H. Karafazlığlu M. 2011. Adapazarı ilçesindeki endüstriyel kaynaklı emisyonların envanterlenmesi. Bitirme Tezi, Müh. Fak. Çevre Müh., Sakarya Üniversitesi.

[11] Öktüren Asri F., Sönmez S., Çıtak S. 2007. Kadmiyumun çevre ve insan sağlı̆̆ı üzerine etkileri. Batı Akdeniz Tarımsal Araştırma Enstitüsü, Akdeniz Üniversitesi Ziraat Fakültesi Toprak Bölümü, Antalya.

[12] Yost K.J., Miles L.J. 1979. Environmental Health Assessment for Cadmium: A Systems Approach, Journal of Environmental Science and Health A., 14: 285-311.

[13] Hegedüs A., Erdei S. Horváth G. 2001. Comparative Studies of H2O2 Detoxifying Enzymes in Green and Greening Barley Seedings under Cadmium Stress. Plant Science,160: 1085-1093.

[14] Laspina N.V., Groppa M.D., Tomaro M.L., Benavides M.P. 2005. Nitric oxide protects sunflower leaves against Cd-induced oxidative stress. Plant Science, 168 (7): 252-260.

[15] Hamutoğlu R., Dinçsoy A.B., Cansaran-Duman D., Aras S. 2012. Biyosorpsiyon, adsorpsiyon ve fitoremediasyon yöntemleri ve uygulamaları. Türk Hijyen ve Deneysel Biyoloji Dergisi, 69 (4): 235- 253.

[16] Sümer A., Adiloğlu S., Çetinkaya O., Adiloğlu A., Sungur A., Akbulak C. 2013. Karamenderes Havzası Topraklarında Bazı Ağır Metallerin $(\mathrm{Cr}, \mathrm{Ni}, \mathrm{Pb})$ Kirliliğinin Araştırılması. Tekirda ğ Ziraat Fakültesi Dergisi, 10 (1): 83-89.

[17] Prasad M.N.V., Malec P., Waloszek A., Bojko M., Strzaka K. 2001. Physiological responses of Lemna trisulca L. (duckweed) to cadmium and copper bioaccumulation. Plant Sci., 161: 881-889.

[18] Hall, J.L. 2002. Cellular meschanisms for heavy metal detoxification and tolerance. J. Exp. Bot., 53: $1-11$.

[19] Verma S., Dubey R.S. 2003. Lead toxicity induces lipid peroxidation and alters the activities of antioxidant enzymes in growing rice plants. Plant Sci., 164: 645- 655.

[20] Zacchini M., Rea E., Tullio M., Agazio M. 2003. Increased antioxidative capacity in maize calli during and after oxidative stress induced by a long lead treatment. Plant Physiol. Bioch.,41: 4954.

[21] Benavides M.P., Gallego S.M., Tomaro M. L. 2005. Cadmium toxicity in plants. Braz. J. Plant Physiol., 17 (1): 21-34.

[22] Dong N., Lib Y., Qia J., Chena Y., Haoa Y. 2018. Nitric oxide synthase-dependent nitric oxide production enhances chilling tolerance of walnut shoots in vitro via involvement chlorophyll fluorescence and other physiological parameter levels. Scientia Horticulturae, 230: 68-77.

[23] Nahar K., Hasanuzzaman M., Alam Md. M., Rahman A., Suzuki T., Fujita M. 2016. Polyamine and nitricoxide cross talk: Antagonistic effects on cadmium toxicity in mung bean plants through upregulating the metal detoxification, antioxidant defense and methylglyoxal detoxification systems. Ecotoxicology and Environmental Safety, 126: 245-255.

[24] Kopyra M., Chudzinska E., Pawlacyzle E.M., Gwozdz E.A. 2005. Nitric oxide diminishees the inhibitory effect of heavy metals an cell divisions in roots of Lupinus luteus. Biological lett. 42 (2): 18.

[25] Xiu-Lan C., Jun-Yu H., Yan-Fang R., Bo C., Hui C. 2012. Effect of nitroprusside on seed germination and seedling physiological characteristics of rice under cadmium stress. Journal of Hunan Agricultural University (Natural Sciences), Chian, 01. 
[26] Zhao X., Chen L., Rehmani M.A., Wang Q., Wang S., Hou P., Li G., Ding Y. 2013. Effect of Nitric Oxide on Alleviating Cadmium Toxicity in Rice (Oryza sativa L.). Journal of Integrative Agriculture, 12 (9): 1540-1550.

[27] Shi H., Ye T., Chan Z. 2014. Nitric oxide-activated hydrogen sulfide is essential for cadmium stress response in bermudagras (Cynodon dactylon (L.). Pers.). Plant Physiology and Biochemistry, 74: 99-107.

[28] López-Orenes A., Martínez-Pérez A., Calderón A.A., Ferrer A. 2014. Pb- induced responses in Zygophyllum fabago plants are organ-dependent and modulated by salicylic acid. Plant Physiology and Biochemistry, 84: 57-66.

[29] Shi Q., Zhu Z. 2008. Effects of exogenous salicylic acid on manganese toxicity, element contents and antioxidative systemin cucumber. Environmental and Experimental Botany, 63: 317-326.

[30] Zawoznik M.S., Groppa M.D., Tomaro M., Benavides M.P. 2007. Endogenous salicylic acid potentiates cadmium-induced oxidative stress in Arabidopsis thaliana. Plant Science, 173: 190197.

[31] Romero-Puertas M.C., Corpas F.J., Rodríguez-Serrano Gómez M., del Rio L.A., Sandalio L.M. 2007. Differential expression and regulation of antioxidative enzymes by cadmium in pea plants. Journal of Plant Physiology, 164: 1346-1357.

[32] Lin R., Wang X., Luo Y., Du W., Guo H., Yin D. 2007. Effects of soil cadmium on growth, oxidative stress and antioxidant system in wheat seedlings (Triticum aestivum $\mathrm{L}$.). Chemosphere, 69: 89-98.

[33] Yilmaz O., Keser S., Tuzcu M., Guvenc M., Cetintas B., Irtegun S., Tastan H., Sahin K. 2009. A Practical HPLC Method to Measure Reduced (GSH) and Oxidized (GSSG) Glutathione Concentrations in Animal Tissues. Journal of Animal and Veterinary Advances, 8 (2): 343-347.

[34] Christie WW. 1990. Gas Chromatography and Lipids. The Oily Pres: Glasgow, 302.

[35] Hara A., Radin N.S. 1978. Lipid extraction of tissues with low-toxicity soluent. Anal.Biochem., 90 (1): 420-426.

[36] Hatata M.M., Abdel-Aal E.A. 2008.Oxidative stres and Antioxidant Defense Mechanismis in Respense to Cadmium Treatments. American-Eurasion J.Agric.\&Environ. Sci, 416: 655-669.

[37] Guo B., Liang Y., Zhu Y. 2009. Does salicylic acid regulate antioxidant defense system, cell death, cadmium uptake and partitioning to acquire cadmium tolerance in rice. Journal of Plant Physiology,166: 20-31.

[38] Y1lmaz D.D., Parlak U.K. 2011. Changes in proline accumulation and antioxidative enzyme activities in Groenlandia densa under cadmium stress. Ecological Indicators, 11: 417-423.

[39] Singh H.P., Batish D.R., Kaur G., Arora K., Kohli K.R. 2008. Nitric oxide (as Sodium Nitroprusside) suplementation ameliorates Cd toxicity in hydroponically grown wheat roots. Environmental and Experimental Botany, 63: 158-167.

[40] He J., Ren Y., Chen X., Chen H. 2014. Protective roles of nitric oxide on seed germination and seedling growth of rice (Oryza sativa L.) under cadmium stress. Ecotoxicology and Environmental Safety, 108: 114-119.

[41] Srivastava S., Mishra S., Tripathi R.D., Dwivedi S., Gupta D.K. 2006. Copper- induced oxidative stress and responses of antioxidants and phytochelatins in Hydrilla verticillata (L.f.) royle. Aquatic Toxicology, 80: 405-415.

[42] Liu Y., Wang X., Zeng G., Qu D., Gu J., Zhou M., Chai L. 2007. Cadmium- induced oxidative stress and response of the ascorbate-glutathione cycle in Bechmeria nivea (L.) gaud. Chemosphere, 69: 99-107.

[43] Benmously-Mlika R., Fenniche S., Marrak H., Jannet S.B., Ammar F.B., Mokhtar I. 2005. F5Nodules pseudoxanthomateux révélant une goutte. Annales de Dermatologie et de Vénéréologie, 132 (3): 282.

[44] Nouairi I., Ghnaya T., Youssef N.B., Zarrouk M., Ghaorbel H.M. 2005. Changes in content and fatty acid profiles of total lipids of two halophytes: Sesuvium portulacastrum and Mesembryanthemum crystailinum under cadmium stress. Journal of Plant Physiology, 163 (11): 1198-1202.

[45] Quariti O., Boussama N., Cherif A., Ghorbal M.H. 1997. Cadmium and Copper Induced Changes In Tomato Membrane Lipids. Phytochemistry, 45 (7): 1343-1350. 
[46] Ivanova A., Krantev A., Stoynova Z. H., Popova L. 2008. Cadmium-Induced changes in maize leaves and the protective role of salicylic acid. Gen. Appl. Plant Physiology, Special Issue, 34: 149-158.

[47] Belkhadi A., Hediji H., Abbes Z., Nouairi I., Barhoumi Z., Zarrouk M., Chaibi W., Djebali W. 2010. Effects of exogenous salicylic acid pre-treatment on cadmium toxicity and leaf lipid content in Linum usitatissimum L. Ecotoxicology and Environmental Safety,73: 1004-101.

[48] Popova L.P., Maslenkova L.T., Yordanova R.Y., Ivanova A.P., Krantev A.P., Szalai G., Janda T. 2009. Exogenous treatment with salicylic acid attenuates cadmium toxicity in pea seedlings. Plant Physiology and Biochemistry, 47: 224-231. 